\title{
MILLING-INDUCED RESET OF THERMOLUMINESCENCE AND DEFORMATION OF HYDROXYL SPECIES IN THE NEAR-SURFACE LAYERS OF QUARTZ GRAINS
}

\author{
AKIHIRO TAKEUCHI ${ }^{1}$ and TETSUO HASHIMOTO ${ }^{2,3}$ \\ ${ }^{1}$ Earthquake Prediction Research Center, Institute of Oceanic Research and Development, Tokai Univeriswty, \\ Orido 3-20-1, Shimizu-ku, Shizuoka 424-8610, Japan \\ ${ }^{2}$ Graduate School of Science and Technology, Niigata University, \\ 8050 Ikarashi-ninocho, Niigata 950-2181, Japan \\ ${ }^{3}$ Department of Chemistry, Faculty of Science, Niigata University, \\ 8050 Ikarashi-ninocho, Niigata 950-2181, Japan
}

\begin{abstract}
Reset mechanisms of thermoluminescence (TL) signals in the near-surface layers ( $\sim 500 \mathrm{~nm}$ thick) of quartz grains during milling are discussed on the basis of the dependence of TL glow-curves and infrared absorption spectra on grain diameter. TL measurements (heating to $370^{\circ} \mathrm{C}$ at $1^{\circ} \mathrm{C} / \mathrm{s}$ ) indicate that the near-surface layer does not seem to emit TL at $\sim 250-400^{\circ} \mathrm{C}$, especially in the blue range, even in TL measurements after re-irradiation. In contrast, the layer seems to emit more TL at $\sim 130^{\circ} \mathrm{C}$ than the inner original quartz. On the other hand, diffused reflection infrared Fourier transform spectrometry indicates that hydroxyl species (e.g. Al-OH, Li-dependent $\mathrm{OH}$ and molecular $\mathrm{H}_{2} \mathrm{O}$ species) are deformed in the near-surface layer. These two series of data suggest that TL recombination sites in the near-surface layer are deformed or broken during milling and contribute to TL emission unusually strongly.
\end{abstract}

Keywords: thermoluminescence (TL), diffused reflection infrared fourier transform (DRIFT) spectrometry, hydroxyl species, quartz, milling.

\section{INTRODUCTION}

Thermoluminescence (TL) dating and electron spin resonance (ESR) dating of fault movements using intrafault materials such as gouges are based on a concept that TL and ESR signals in the materials are reset during faulting due to frictional heating (Ikeya et al., 1982; Nishimura and Horinouchi, 1989; Lee and Schwarcz, 1993, 1994; Singhvi et al., 1994). However, the complete resetting of TL and ESR signals is often considered to be doubtful in some laboratory experiments (Toyoda et al., 2000) and measurements of natural gouges (Fukuchi and Imai, 1998). On the other hand, it is often needed to crush and mill geological and archaeological samples to extract quartz and feldspar grains for TL and ESR dating. In case of coarse grains, the near-surface layer is usually removed by HF etching (Scholefield and Prescott, 1999;

Corresponding author: A. Takeuchi

e-mail: atakeuchi@sems-tokaiuniv.jp

ISSN 1897-1695 (online), 1733-8387 (print) (C) 2008 GADAM Centre,

Institute of Physics, Silesian University of Technology.

All rights reserved.
Tsuchiya et al., 2000; Nakagawa and Hashimoto, 2003). However, in case of fine grains, it is hard to do it. Therefore, influence of crushing and milling on TL and ESR signals as well as alpha-damage from ambient materials remains in the layer.

From the grain diameter dependence of the TL intensity in milled quartz grains, we found that TL signals were reset only in the near-surface layers $(\sim 500 \mathrm{~nm}$ thick; Takeuchi et al., 2004, 2006). This layer is equivalent to the surface disordered layer ( 10-1000 nm thick), normally highly disturbed and/or amorphous through thermal and mechanical damage during faulting and milling (Moody and Hundley-Goff, 1980; Yund et al., 1990). Fig. 1 shows a representative diagram of a milled quartz grain (modified from Takeuchi et al., 2006). The possible mechanisms for the surface resetting of TL signals are:

1) Recombination of TL-holes and thermally stimulated electrons as well as ions that are mobilized by frictional heat or mechanical stress. 
2) Energy state change of TL recombination sites that are deformed or broken by mechanical stress.

These two mechanisms must offer a complex relationship (Takeuchi et al., 2006).

The hydroxyl species is the most populous impurity in quartz and often cited to have a role in the TL mechanism. Based on ESR measurements of hydrogen radicals and Al-hole centres in various quartz samples after isochronal annealing treatments, Hashimoto et al. (2000) concluded that irradiation-induced hydrogen radicals from hydroxyl species including $\mathrm{H}_{2} \mathrm{O}$ combined with Alhole centres below room temperature. It leads to decrease of the Al-hole centre population and the TL intensity above room temperature. Based on ESR measurements and infrared spectroscopy of natural crystalline quartz, Hashimoto et al. (2006) proposed a similar mechanism. Therefore, we have focused here on the hydroxyl species that seems to be an important factor connecting the proposed mechanisms (1) and (2).

In this paper, we conduct measurements of blue-TL (BTL) and red-TL (RTL) from milled quartz grains (section 2) and diffused reflection infrared Fourier transform (DRIFT) spectrometry of hydroxyl species in the same grains (section 3). Based on these results, we propose a dynamic model of TL resetting in the near-surface layers during milling (section 4).

\section{TL MEASUREMENTS}

\section{Method}

The sample was grains of pegmatite quartz from Marumori, Miyagi prefecture, Japan. Because this sample had been already prepared for our earlier studies (Takeuchi et al., 2006), the sample preparation is described briefly here. A quartz block was crushed into small fragments $(<1 \mathrm{~mm})$ and then treated with $\mathrm{NaOH}$ and $\mathrm{HCl}$ solutions. After resetting natural TL by annealing at $450^{\circ} \mathrm{C}$ for $30 \mathrm{~min}$, the fragments were irradiated with $\gamma$-rays of ${ }^{137} \mathrm{Cs}$ ( $1 \mathrm{kGy}$ at $3 \mathrm{~Gy} / \mathrm{min}$ ) as the "pseudonatural dose". After that, they were milled into grains. A half portion was treated with HF solution to etch the nearsurface layers. Finally, the etched and unetched grains were sieved into several sizes ( $\sim 5.1-280 \mu \mathrm{m}$ diameter). In this paper, these samples are called the "pseudo-natural" grains.

It is already known that the "pseudo-natural" grains have three distinctive TL peaks, separable into peak A $\left(470 \mathrm{~nm}, 200^{\circ} \mathrm{C}\right)$, peak $\mathrm{B}\left(615 \mathrm{~nm}, 340^{\circ} \mathrm{C}\right)$ and peak $\mathrm{C}\left(620 \mathrm{~nm}, 205^{\circ} \mathrm{C}\right)$ as shown in Fig. 2 (modified from Takeuchi et al. (2006)). In this paper, an automated luminescence measurement system (Hashimoto et al., 2002) was used for all BTL and RTL measurements with the optical conditions as shown in Table 1. All aliquots (2.7-2.9 $\mathrm{mg}$ ) from the "pseudo-natural" grains were heated from $50^{\circ} \mathrm{C}$ to $370^{\circ} \mathrm{C}$ at $1{ }^{\circ} \mathrm{C} / \mathrm{s}$ after preheating at $80^{\circ} \mathrm{C}$ for $5 \mathrm{~min}$. After that, they were irradiated with $\mathrm{X}$-ray $(50 \mathrm{kV}, 0.15 \mathrm{~mA}$, through $200 \mu \mathrm{m} \mathrm{Al} \mathrm{filter)} \mathrm{for}$ $200 \mathrm{~s}$, equivalent to about $9.8 \mathrm{~Gy}$ at $2.9 \mathrm{~Gy} / \mathrm{min}$. Just after the X-ray irradiation, TL measurements were conducted under the same preheating and heating condition. Such $\mathrm{X}$-ray irradiation and subsequent TL measurements were repeated two more times. In this paper, these samples are called the "X-ray 1-cycle" grains, the "X-ray 2-cycle" grains and the "X-ray 3-cycle" grains.

\section{Results}

Fig. 3 shows part of the results: TL glow curves of the "X-ray 1-cycle" grains (fine to coarse, $\sim 5.1-280 \mu \mathrm{m}$ diameter) with a curve of the "pseudo-natural" grains (coarsest, $\sim 280 \mu \mathrm{m}$ diameter) as a reference. The curves are the averages obtained from several aliquots for each sample. BTL is normalized using the $340^{\circ} \mathrm{C}$ intensity of the pseudo-natural curve for each grain size. RTL is normalized using the peak B intensity of the pseudo-natural curve for each grain size. This normalization can eliminate the influence of the scattering loss in the TL photons through the grains. Of course, the pseudo-natural curves match with the TL spectra observed earlier (Takeuchi et al., 2006) as shown in Fig. 2. However, the 1-cycle curves are quite different from the pseudo-natural curves, i.e. peaks $\mathrm{A}$ and $\mathrm{C}$ are absent in the 1-cycle curves. It appears that peaks $\mathrm{A}$ and $\mathrm{C}$ start growing up after longer $\mathrm{X}$-ray irradiation.

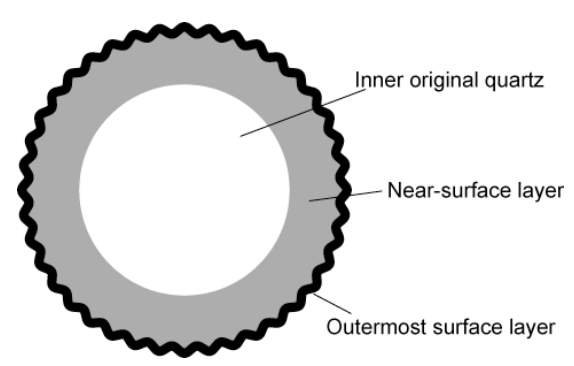

Fig. 1. A representative diagram of a milled quartz grain (modified from Takeuchi et al. (2006)). The near-surface layer is mechanically and thermally damaged during milling. The outermost surface layer adheres $\mathrm{H}_{2} \mathrm{O}$ molecules and ions.

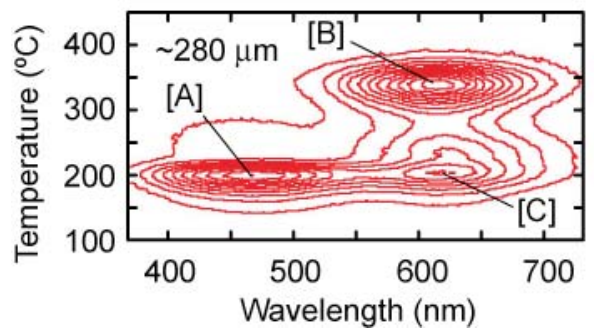

Fig. 2. An example of TL spectra obtained previously (modified from Takeuchi et al. (2006)). The grains sample ( 280 $\mu$ m diameter) was heated from $100^{\circ} \mathrm{C}$ to $450^{\circ} \mathrm{C}$ at $1^{\circ} \mathrm{C} / \mathrm{s}$ after preheating at $100^{\circ} \mathrm{C}$ for $1 \mathrm{~min}$. The grains were dosed $1 \mathrm{kGy}$ at $3 \mathrm{~Gy} / \mathrm{min}$ before milling.

Table 1. Optical conditions for BTL and RTL measurements.

\begin{tabular}{llll}
\hline TL & $\begin{array}{l}\text { Photomultiplier tube } \\
\text { (Maker) }\end{array}$ & Filters (Maker) & $\begin{array}{l}\text { Detection } \\
\text { window (nm) }\end{array}$ \\
\hline BTL & R585S (Hamamatsu) & $\begin{array}{l}\text { B-390 (Hoya) } \\
\text { GG-420 (Schott) }\end{array}$ & $\sim 400-500$ \\
\hline RTL & R649S $^{*}$ (Hamamatsu) & $\begin{array}{l}\text { R-60 (Toshiba) } \\
\text { IR-cut filter (Eagle) } \\
\text { SV0650 (Asahi) }\end{array}$ \\
\hline
\end{tabular}

${ }^{\circ}$ Cooled to $-20^{\circ} \mathrm{C}$ to reduce noise. 
(a) BTL of etched grains

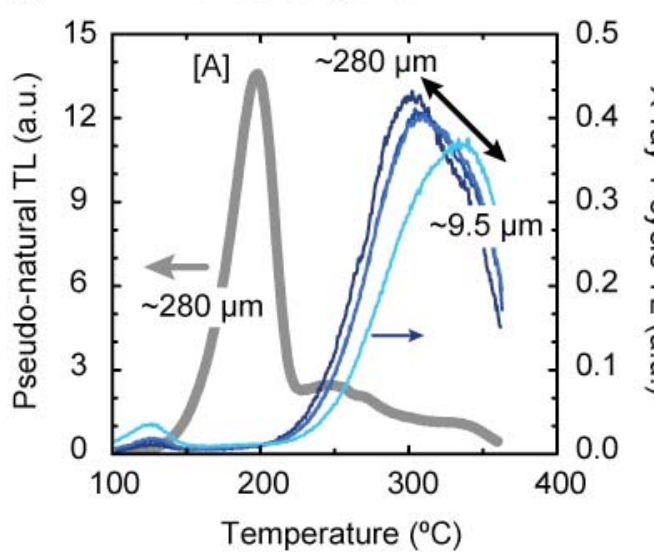

(c) RTL of etched grains

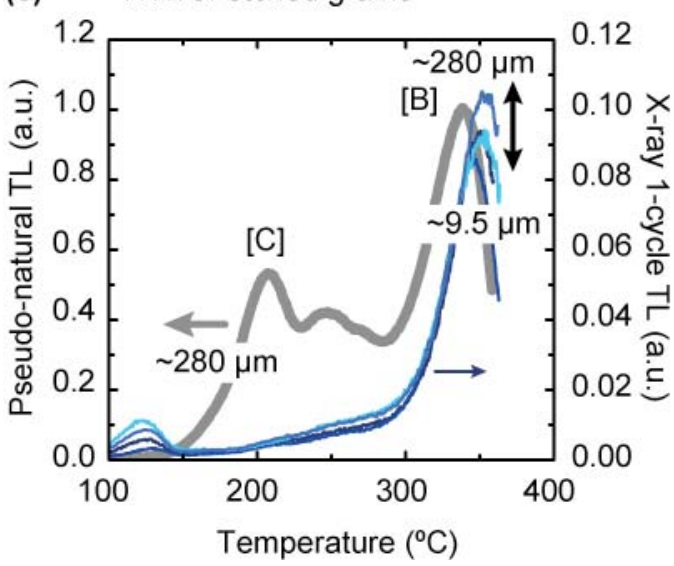

(b) BTL of unetched grains

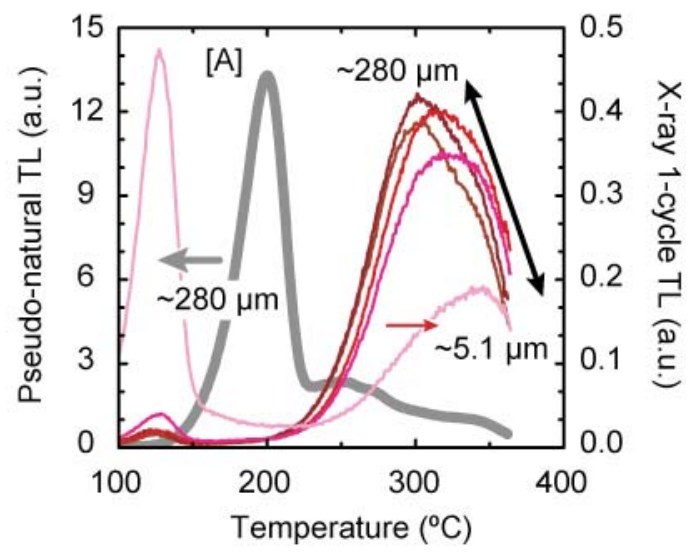

(d) RTL of unetched grains

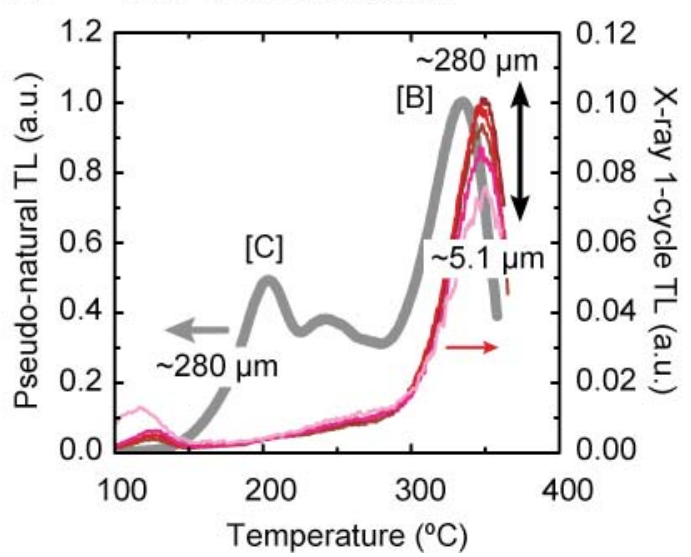

Fig. 3. TL glow curves of milled quartz grains. (a) Normalized BTL of etched grains. (b) Normalized BTL of unetched grains. (c) Normalized RTL of etched grains. (d) Normalized RTL of unetched grains.

BTL, especially of the 1-cycle grains, shows a broad peak at $\sim 250-400^{\circ} \mathrm{C}$ that seems to involve more than one peak. The mixed peak height decreases with decrease in the grain diameter. The apparent peak temperature increases with decrease of the grain diameter due to change of the ratio of the peaks. In contrast, the $130^{\circ} \mathrm{C}$ peak increases with decrease of the grain diameter, especially; the finest unetched grains show a prominent $130^{\circ} \mathrm{C}$ peak. On the other hand, RTL of both pseudo-natural and 1cycle grains shows a single peak (peak B) in the same temperature range. Similar to BTL, this peak decreases with decrease of the grain diameter and the $130^{\circ} \mathrm{C}$ peak increases with decrease of the grain diameter.

\section{Brief discussion}

As mentioned in the Introduction, the pseudo-natural curve of unetched grains does not include the TL signals from the near-surface layer because the TL signals in the layers are reset during milling. Because the normalization of the TL grow curves eliminates the influence of the scattering loss in TL photons through the grains, the 1-cycle curves of the etched grains should have same intensity, independent of the grain diameter. Moreover, if TL is emitted from the near-surface layers of unetched grains after X-ray irradiation, its influence should be superimposed on the TL emission from the inner normal quartz. Because the volume contribution of the layers against the total volume increases with decrease of the grain diameter, the 1-cycle TL intensity of the unetched grains should increase with decrease of the grain diameter. However, the TL intensities of both etched and unetched grains decrease with decrease of the grain diameter. The 2- and 3-cycle curves also show similar tendency.

Fig. 4 shows the 1-, 2- and 3-cycle TL intensity (peak height, normalized) against the grain diameter. As mentioned above, peak B decreases with decrease of the grain diameter. In addition, its intensity decreases with repeat of X-ray irradiation and TL measurements. In the coarse grains range, the intensity seems to settle down to a level after two cycles, while, in the fine grains range, the intensity seems to continue decreasing even after three cycles. Thus, the degree of the TL sensitivity change depends on the grain diameter. Such tendency causes apparently the grain diameter dependence of peak B (Fig. 3). Here, because the complicate BTL peaks $\left(\sim 250-400^{\circ} \mathrm{C}\right)$ cannot be separated clearly, we cannot depict their tendency correctly. However, it is expected that their tendency will be similar to that of peak B in Fig. 4. When we compare the heights of the TL at $\sim 250-400^{\circ} \mathrm{C}$ between etched and unetched grains in the same or similar grain sizes, there seems no significant difference in intensity. These results 

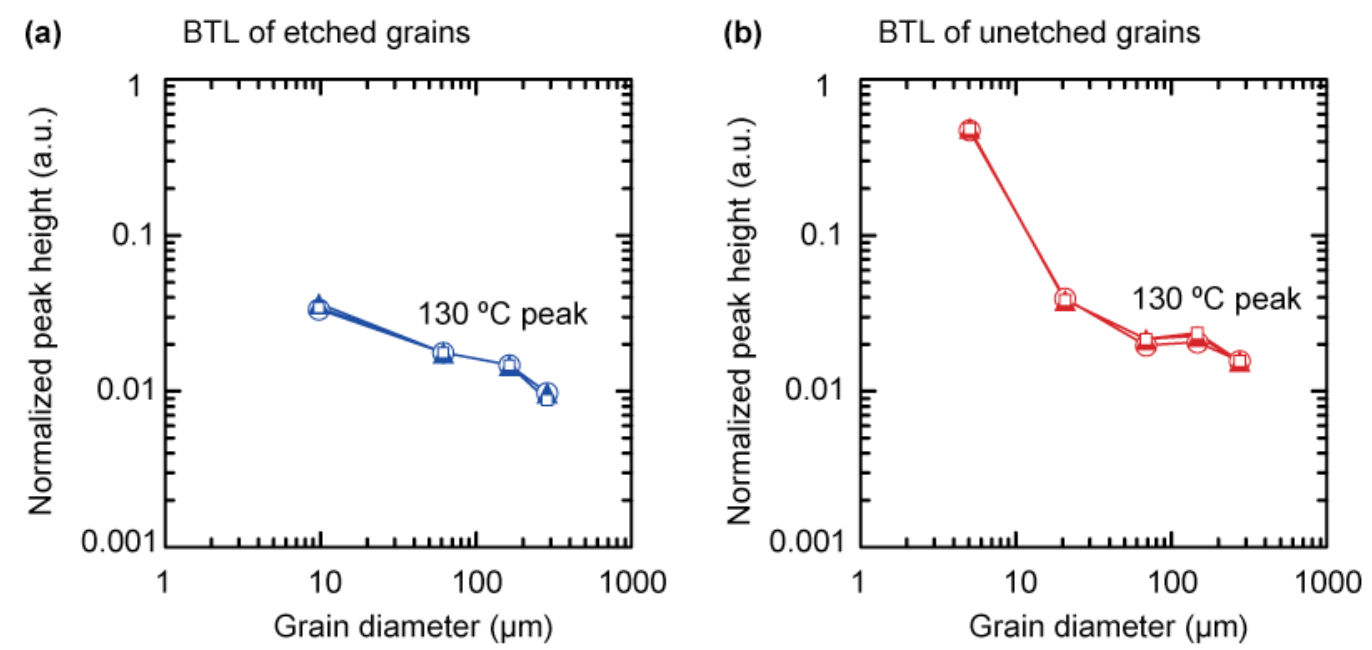

(c) RTL of etched grains

(d) RTL of unetched grains
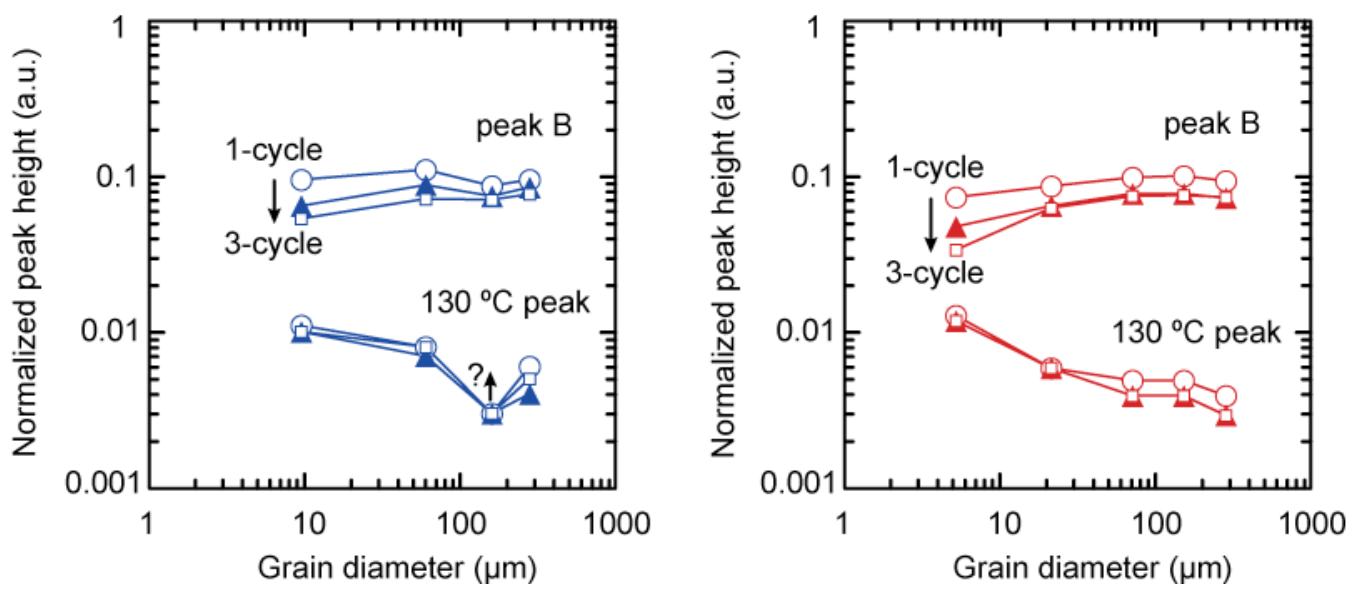

Fig. 4. TL sensitivity changes during three cycles of X-ray irradiation and TL measurements. (a) Normalized BTL peak heights of etched grains. (b) Normalized BTL peak heights of unetched grains. (c) Normalized RTL peak heights of etched grains. (d) Normalized RTL peak heights of unetched grains.

indicate that the $\mathrm{TL}$ at $\sim 250-400^{\circ} \mathrm{C}$ is not emitted from the near-surface layer even after X-ray irradiation.

In contrast with the TL peaks at $\sim 250-400^{\circ} \mathrm{C}$, the $130^{\circ} \mathrm{C}$ peaks in both BTL and RTL increase with decrease of the grain diameter (Fig. 3). Their intensity does not change during three cycles of TL measurements (Fig. 4). When we compare their heights in BTL between etched and unetched grains in the same or similar grain sizes, the heights of unetched grains are higher than those of etched grains. Through these results, we can say that the recombination sites of the $130^{\circ} \mathrm{C} \mathrm{TL}$, especially $\mathrm{BTL}$, peak are localized near surface.

\section{DRIFT SPECTROMETRY}

\section{Method}

The same milled quartz grains, the "pseudo-natural" grains, were used for DRIFT spectrometry. Fig. 5 shows a schematic diagram of the set-up. Each grains sample was loosely packed in a small metal cell (inside: $9.8 \mathrm{~mm} \phi, 1.7 \mathrm{~mm}$ depth). The cell was placed in a temperature-controlled box (Linkam, FTIR600 with LK-1500 and L-600A) filled with $\mathrm{N}_{2}$ gas and cooled to
$-195.0 \pm 0.5^{\circ} \mathrm{C}$. IR scan was performed using a Fourier transform IR microscopic spectrometer (Perkin Elmer, AutoIMAGE System and Spectrum GX FT-IR System). The scan range was $4000-2500 \mathrm{~cm}^{-1}$ with $1 \mathrm{~cm}^{-1}$ interval. The aperture size was $300 \times 300 \mu \mathrm{m}^{2}$. The scan was repeated 64 times for each area to make the spectrum clear. The average spectrum was then obtained from random 30 scan areas for each sample. During preparing and measuring, the samples were kept under dark to avoid light bleaching effects on the TL signals.

\section{Results}

Fig. 6 shows all average IR absorbance spectra. The spectra are transformed from the original DRIFT spectra using the Kubelka-Munk theory. The mean absorbance level decreases with decrease of the grain diameter for both etched and unetched grains samples. This trend is concordant with earlier works on IR spectrometry using various mineral grains (Cooper and Mustard, 1999; Le Bras and Erard, 2003). Two sharp peaks at 3375 and $3465 \mathrm{~cm}^{-1}$ are attributed to Li-dependent $\mathrm{OH}$ and $\mathrm{Al}-\mathrm{OH}$ species, respectively. Here, Li-dependent $\mathrm{OH}$ is a hydroxyl species interacting with $\mathrm{Li}^{+}$, but the detailed struc- 
ture is still unknown. On the other hand, Al-OH is a hydroxyl species associated with $\mathrm{Al}^{3+}$ substituted for $\mathrm{Si}^{4+}$. A broad peak ranging $~ 3800-2800 \mathrm{~cm}^{-1}$ is well known as a molecular $\mathrm{H}_{2} \mathrm{O}$ species in and on the grains (Kats, 1962; Iwasaki and Iwasaki, 1993).

Fig. 7 shows the grain diameter dependences on the absorbance peak areas: Li-dependent $\mathrm{OH}$ species $\left(3475 \mathrm{~cm}^{-1}\right)$, Al-OH species $\left(3365 \mathrm{~cm}^{-1}\right)$, and molecular $\mathrm{H}_{2} \mathrm{O}$ species $\left(\sim 3800-2800 \mathrm{~cm}^{-1}\right)$. The peak areas decrease with decrease of the grain diameter for both etched and unetched grains. For Li-dependent $\mathrm{OH}$ and $\mathrm{Al}-\mathrm{OH}$ species, the intensities of the etched grains seem to have a linear dependence on the grain diameter in log-log plots. In the coarse grain ranges, the intensities of the unetched grains are slightly larger than those of the etched. However, in the medium and fine grains ranges, they rapidly decrease and become lower than the etched grains. On the other hand, for molecular $\mathrm{H}_{2} \mathrm{O}$ species, the intensity of the unetched grains is slightly larger than that of the etched in all ranges.

\section{Brief discussion}

For Li-dependent $\mathrm{OH}$ and $\mathrm{Al}-\mathrm{OH}$ species (Figs 7a and $\mathbf{7 b}$ ), we presume that the solid linear lines are the base lines for the etched grains under the present meas-

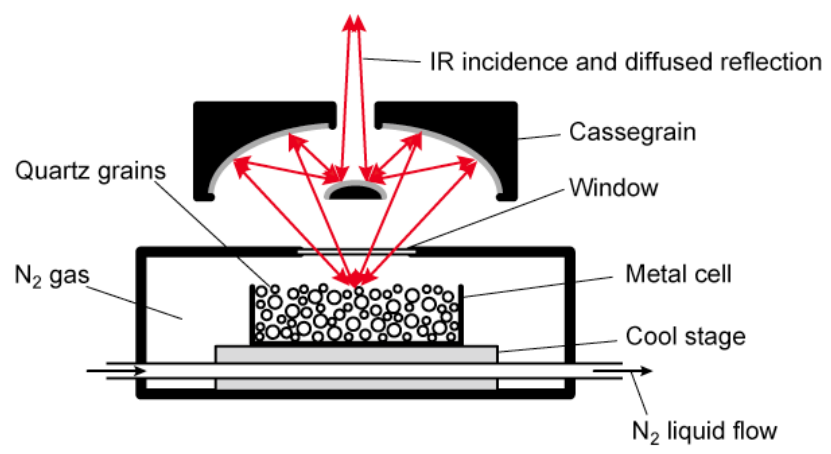

Fig. 5. Schematic diagram of the set-up for DRIFT spectrometry at $-195^{\circ} \mathrm{C}$.

(a) Etched grains

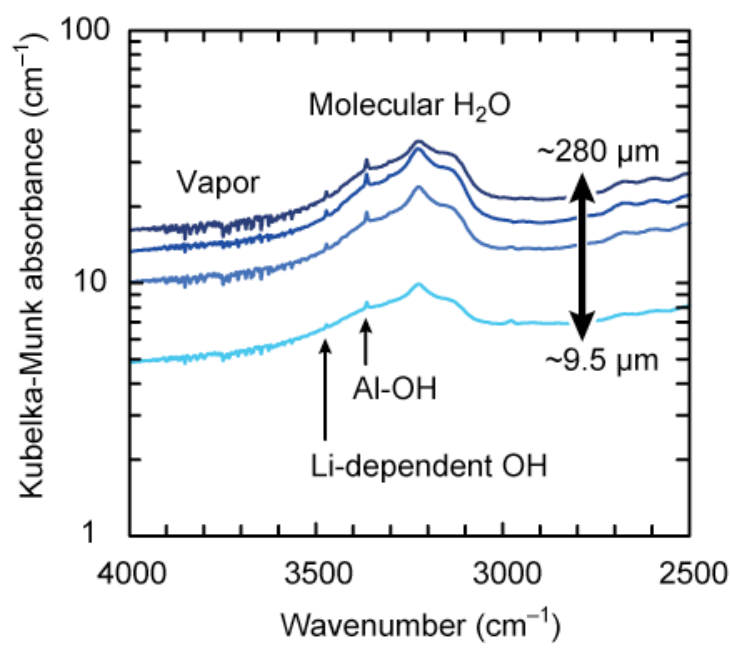

urement condition and the dotted linear lines are the base lines for the unetched grains. The gap between the solid and dotted lines would be attributed to difference of the surface roughness. There are a number of very fine grains ( 1-2 $\mu \mathrm{m}$ diameter) adhering to the unetched grain surface (Fig. 8) even though all samples were washed with distilled water in an ultra sonic bath after sieving. Their size $(\sim 1-2 \mu \mathrm{m}$ diameter) is roughly equivalent to a half wavelength of the IR in question $\left(\sim 3400 \mathrm{~cm}^{-1} \rightarrow \sim 3 \mu \mathrm{m}\right)$. The IR passing through these very fine grains causes phase alteration and leads to cancellation with the nonpassing IR, which can cause a "quasi-increase" of the IR absorbance in the unetched grains. Therefore, for the unetched grains, the deviation from the dotted line means the "real-change" in intensity. This deviation suggests deformation and/or breakage of Li-dependent $\mathrm{OH}$ and Al$\mathrm{OH}$ species near surface because deformed or broken species do not vibrate as usual and do not absorb the incoming IR beam as usual (i.e. $3475 \mathrm{~cm}^{-1}$ and $3365 \mathrm{~cm}^{-1}$ at $-195^{\circ} \mathrm{C}$, respectively).

Similar to Li-dependent $\mathrm{OH}$ and $\mathrm{Al}-\mathrm{OH}$ species, the gap in the IR absorbance for molecular $\mathrm{H}_{2} \mathrm{O}$ species (Fig. 7c) between the etched and unetched grains would be due to difference of the surface roughness. The spectrum of molecular $\mathrm{H}_{2} \mathrm{O}$ species for the finest unetched grains (Fig. 6b) is clearly deformed. This means deformation of molecular $\mathrm{H}_{2} \mathrm{O}$ species near surface like Lidependent $\mathrm{OH}$ and $\mathrm{Al}-\mathrm{OH}$ species. This effect should appear as the downward-pointing deviation from the dotted line in Fig. 7c. On the other hand, there is a difference in the location between molecular $\mathrm{H}_{2} \mathrm{O}$ species and other two $\mathrm{OH}$ species; molecular $\mathrm{H}_{2} \mathrm{O}$ species is located not only in a grain but also on the grain surface (Fig. 1). The influence of molecular $\mathrm{H}_{2} \mathrm{O}$ species on the surface increases with decrease of the grain diameter because the specific surface increases with decrease of the grain diameter. This effect should appear as the upward-pointing deviation from both lines in Fig. 7c. As a result, the grain diameter dependence of the IR absorbance intensity of molecular $\mathrm{H}_{2} \mathrm{O}$ species is non-linear in log-log plots. (b) Unetched grains

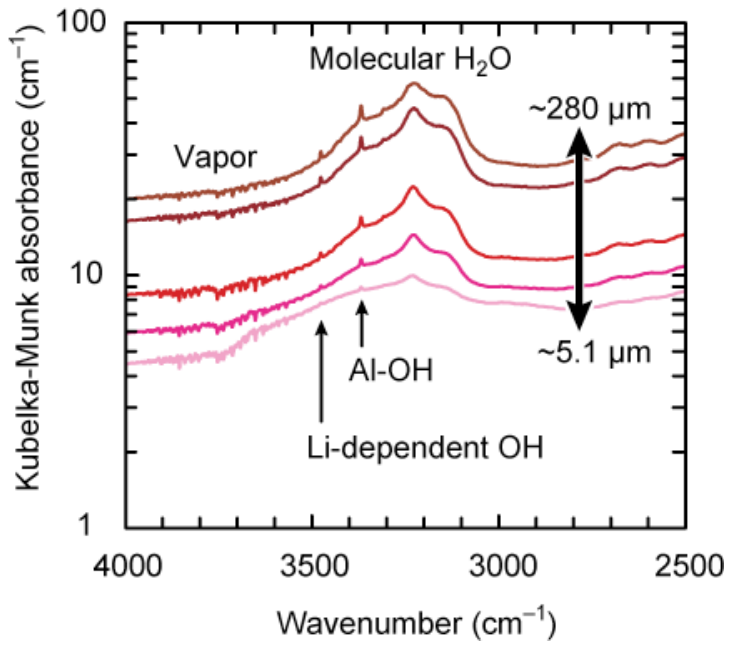

Fig. 6. DRIFT spectra of milled quartz grains in Kubelka-Munk transformed absorbance at $-195^{\circ} \mathrm{C}$. (a) Etched grains. (b) Unetched grains. The samples were dosed with $1 \mathrm{kGy}$ at $3 \mathrm{~Gy} / \mathrm{min}$ before milling. 

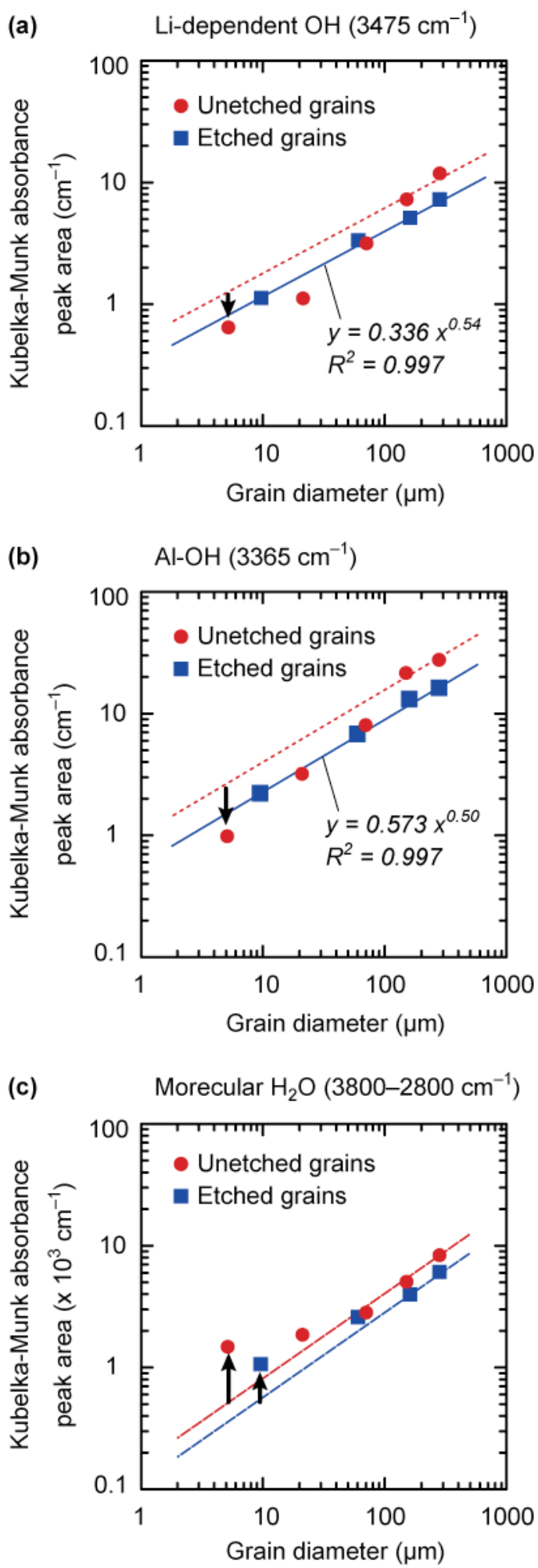

Fig. 7. IR absorbance intensity of milled quartz grains against the grain diameter at $-195^{\circ} \mathrm{C}$. (a) Li-dependent $\mathrm{OH}$ species $\left(3475 \mathrm{~cm}^{-1}\right)$. (b) Al-OH species $\left(3365 \mathrm{~cm}^{-1}\right)$. (c) Molecular $\mathrm{H}_{2} \mathrm{O}$ species ( $\sim 3800-$ $2800 \mathrm{~cm}^{-1}$ ). The intensity means the peak area in Kubelka-Munk transformed absorbance and are calculated from the spectra in Fig. 5.

\section{DISCUSSION AND CONCLUSIONS}

In our previous studies (Takeuchi et al., 2004, 2006), we concluded that TL signals are mostly reset in the nearsurface layers $(\sim 500 \mathrm{~nm}$ thick) of milled quartz grains, (a)

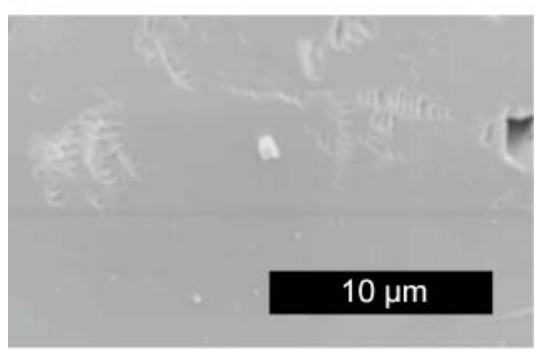

(b)

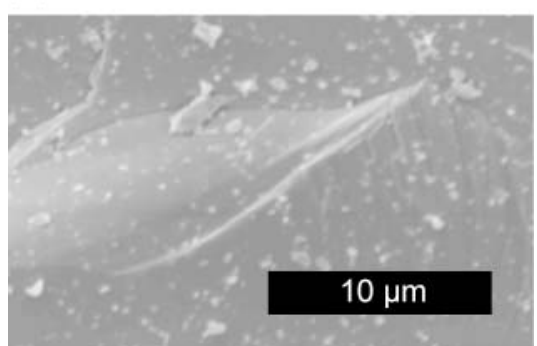

Fig. 8. SEM images of milled quartz grains. (a) Etched grain surface. (b) Unetched grain surface with very fine grains.

suggesting (a) recombination of TL-holes with thermally stimulated electrons or ions or (b) deformation or breakage of TL-holes. In our present study, we further found and suggested:

(I) The near-surface layer does not seem to emit TL (BTL and RTL at $\sim 250-400^{\circ} \mathrm{C}$ ) even after reirradiation.

(II) The near-surface layer emits the $130^{\circ} \mathrm{C}$ TL stronger than the inner original quartz, remarkable in BTL.

(III) The near-surface layer does not show IR absorption of Li-dependent $\mathrm{OH}, \mathrm{Al}-\mathrm{OH}$ and molecular $\mathrm{H}_{2} \mathrm{O}$ species as usual, suggesting deformation and/or breakage of the hydroxyl species.

Our earlier finding is concordant with the (I) and (II). The structure of the near-surface layer is highly disturbed and/or amorphous due to thermal and mechanical damage (Moody and Hundley-Goff, 1980; Yund et al., 1990) and often called the surface disordered layer. This is concordant with the (III). Therefore, the states of the TL recombination sites for BTL and RTL $\left(\sim 250-400^{\circ} \mathrm{C}\right)$ in the layer are far from those in the inner original quartz as well as those of hydroxyl species. Heating to $\sim 370^{\circ} \mathrm{C}$ for TL measurements in present study may not cure the sites of their deformed and/or broken structures in the nearsurface layer. Therefore, the layer would remain disordered structure even after three cycles of irradiation and TL measurements.

The (II) suggests that the hole and/or electron trapping sites of the $130^{\circ} \mathrm{C}$ TL peak in BTL and RTL correspond to "deformed or disturbed sites" in the near-surface layer rather than "normal sites" like ones in the inner original quartz. From the viewpoint of the band model, the energy levels of these sites should be different from the normal ones. These sites seem to be get activated as TL recombination sites from non-TL recombination sites, or this TL peak may be a deformed type of the so-called $110^{\circ} \mathrm{C}$ TL peak or the TL peaks at $\sim 250-400^{\circ} \mathrm{C}$. Heating to about $370^{\circ} \mathrm{C}$ in the present study would not cure the 
(a)<smiles>CO[Al](OC)OC</smiles>

Normal Al-OH species

Deformed or broken $\mathrm{Al}-\mathrm{OH}$ species

(b)<smiles>CO[Al](OC)OC</smiles>

(c)

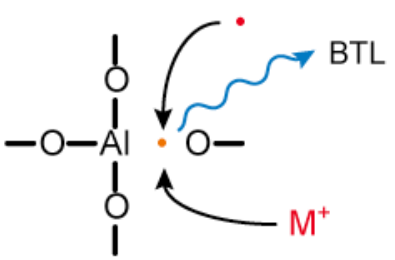

Normal recombination

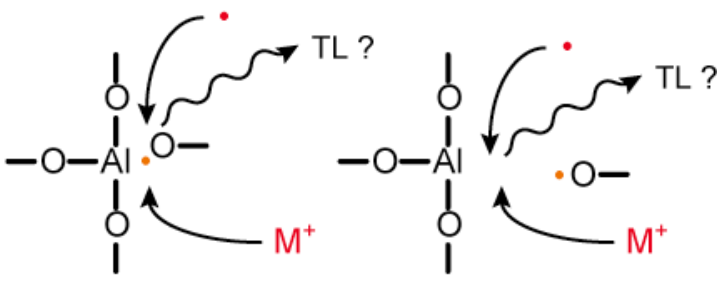

Deformed or broken recombination

Fig. 9. Dynamic model of TL resetting in the near-surface layer during milling. (a) Deformation or breakage of Al-OH species. When the $\mathrm{OH}$ is cramped, it cannot vibrate as usual. When the $\mathrm{OH}$ is away from the $\mathrm{A}^{\beta^{3+}}$ site, its vibration is freed from the influence of the $A /^{3^{+}}$. (b) Deformation or breakage of Al-hole centre. Similar to Al-OH species, Al-hole centre is deformed or broken. The trap depth of the hole strongly depends on the interaction with the surrounding anions and cations, so that the trap depth of the deformed or broken hole is different from the normal one. (c) Recombination and TL emission/non-emission of normal and deformed/broken Al-hole centres. At recombination with an electron or ion freed by frictional heating or mechanical stress, the process and energy gap of the de-excitation are different from the normal one, so that TL observed may not be like the conventional one.

sites of their deformation and/or disturbance, so that the sensitivities of the $130^{\circ} \mathrm{C}$ TL peaks, "deformed or disturbed sites", keep a level even after repeat of irradiation and TL measurement.

Fig. 9 shows a dynamic model of TL resetting in the surface disordered layer of a quartz grain during milling. Al-hole centre $\left(\left[\mathrm{AlO}_{4} / h^{+}\right]^{0}\right)$ is considered here because it is widely cited as a hole source or recombination site for TL, especially BTL (Martini et al., 1995; Hashimoto et al., 2000; Itoh et al., 2002). Similar to Al-OH species (Fig. 9a), Al-hole centre in the near-surface layer is deformed or broken through mechanical stress during milling (Fig. 9b). The energy level of the deformed or broken hole is different from the original one. At the same time, a thermally stimulated electron or ion comes to this site and recombines (Fig. 9c). However, the process and energy gap of de-excitation are different from the original, so that TL as usual is not generated.

In TL and ESR dating of fault movements using intrafault materials, it is recommended to use fine grains (Buhary et al., 1988; Takeuchi et al., 2006). However, as the main part of a fine grain is the near-surface layer (surface disordered layer) in which TL recombination sites do not emit TL, the TL (and probably ESR) signals will be very weak or absent. Even if a geological period gradually cures this layer of its damage, there seems to be differences in the equivalent dose encountered by the inner original quartz and the near-surface layer. This may give rise to incorrect age estimation. This makes TL and ESR dating of intrafault materials difficult.

In conclusion, we proposed models of detail TL resetting in the near-surface layers (surface disordered layers) of quartz grains during milling based on combination of TL measurements and DRIFT spectrometry. In the nearsurface layer, TL recombination sites as well as $\mathrm{OH}$ species are deformed and/or broken and do not work as usual $\mathrm{TL}$ recombination sites. In the present study, we also discovered that TL sensitivity depends on the grain size. They expose new questions about detail TL mechanisms that need further studies to be answered.

\section{REFERENCES}

Le Bras A and Erard S, 2003. Reflectance spectra of regolith analogs in the mid-infrared: effects of grain size. Planetary Space and Science 51(4-5): 281-294, DOI 10.1016/S0032-0633(03)00017-5.

Buhary WM, Schwarcz HP and Grün R, 1988. ESR dating of fault gouge: the effect of grain size. Quaternary Science Reviews 7(34): 515-522, DOI 10.1016/0277-3791(88)90055-8. 
Cooper CD and Mustard JF, 1999. Effects of very fine particle size on reflectance spectra of smectite and palagonitic soil. Icarus 142(2): 557-570, DOI 10.1006/icar.1999.6221.

Fukuchi T and Imai N, 1998. Resetting experiment of $\mathrm{E}^{\prime}$ centers by natural faulting - the case of the Nojima earthquake fault in Japan. Quaternary Science Reviews 17(11): 1063-1068, DOI 10.1016/S0277-3791(97)00102-9.

Hashimoto T, Hase H, Hong D, Fujita H and Katayama H, 2000. Correlation of aluminum hole centers with hydrogen radicals from $\gamma$ irradiated quartz of different origins. The Journal of Nuclear and Radiochemical Sciences 1(1): 47-50.

Hashimoto T, Nakagawa T, Hong DG and Takano M, 2002. An automated system for both red/blue thermoluminescence and optically stimulated luminescence measurement. Journal of Nuclear Science and Technology 39(1): 108-109, DOI 10.3327/jnst.39.108.

Hashimoto T, Yamaguchi T, Tajika Y, Takeuchi A and Yawata T, 2006. Behavior of TL-glowcurves for natural quartz samples from liquid-nitrogen temperature up to room temperature. Radiation Measurements 41(6): 671-676, DOI 10.1016/j.radmeas.2006.04.011.

Ikeya M, Miki T and Tanaka K, 1982. Dating of a fault by electron spin resonance on intrafault materials. Science 215(4538): 1392-1393, DOI 10.1126/science.215.4538.1392.

Itoh N, Stoneham D and Stoneham AD, 2002. Ionic and electronic processes in quartz: mechanisms of thermoluminescence and optically stimulated luminescence. Journal of Applied Physics 92(9): 5036-5044, DOI 10.1063/1.1510951.

Iwasaki $\mathrm{F}$ and Iwasaki $\mathrm{H}$, 1993. Impurity species in synthetic and Brazilian natural quartz. Japanese Journal of Applied Physics 32 Part 1(2): 893-901, DOI 10.1143/JJAP.32.893.

Kats A, 1962. Hydrogen in alpha-quartz. Philips Research Reports 17: 133-195.

Lee HK and Schwarcz EP, 1993. An experimental study of shearinduced zeroing of ESR signals n quartz. Applied Radiation and Isotopes 44(1-2): 191-195, DOI 10.1016/0969-8043(93)90218-Y.

Lee HK and Schwarcz EP, 1994. Criteria for complete zeroing of ESR signals during faulting of the San Gabriel fault zone, southern California. Tectonophysics 235(4): 317-337, DOI 10.1016/00401951(94)90192-9.
Martini M, Paleari A, Spinolo G and Vedda V, 1995. Role of $\left[\mathrm{AlO}_{4}\right]^{0}$ centers in the 380-nm thermoluminescence of quartz. Physical Review B 52(1): 138-142, DOI 10.1103/PhysRevB.52.138.

Moody JB and Hundley-Goff EM, 1980. Microscopic characteristics of orthoquartzite from sliding friction experiments. II. Gouge. Tectonophysics 62(3-4): 301-319, DOI 10.1016/0040-1951(80)901985.

Nakagawa T and Hashimoto T, 2003. Sensitivity changes of OSL and RTL signal from natural RTL quartz with annealing treatment. Radiation Measurements 37(4-5): 397-400, DOI 10.1016/S13504487(03)00065-9.

Nishimura S and Horinouchi T, 1989. Thermoluminescence ages of some quartz in fault gouges. Journal of Physics of the Earth 37: 313-323.

Scholefield RB and Prescott JR, 1999. The red luminescence of quartz: 3-D spectral measurements. Radiation Measurements 30(1): 83 95, DOI 10.1016/S1350-4487(98)00094-8.

Singhvi AK, Banerjee D, Pande K, Gogte V and Vadiya KS, 1994 Luminescence studies on neotectonic events in South-Central Kumaun Himalaya - a feasibility study. Quaternary Science Reviews 13(5-7): 595-600, DOI 10.1016/0277-3791(94)90083-3.

Takeuchi A, Nagahama H and Hashimoto T, 2004. Surface electrification and charge trapping centers. Physics and Chemistry of the Earth 29(4-9): 359-366, DOI 10.1016/j.pce.2003.09.016.

Takeuchi A, Nagahama H and Hashimoto T, 2006. Surface resetting of thermoluminescence in milled quartz grains. Radiation Measurements 41(7-8): 826-830, DOI 10.1016/j.radmeas.2006.05.009.

Toyoda S, Rink WJ, Schwarcz HP and Rees-Jones J, 2000. Crushing effects on TL and OSL on quartz: relative to fault dating. Radiation Measurements 32(5-6): 667-672, DOI 10.1016/S13504487(00)00088-3.

Tsuchiya N, Suzuki T and Nakatsuka K, 2000. Thermoluminescence as a new research tool for the evaluation of geothermal activity of the Kakkonda geothermal system, northeast Japan. Geothermics 29(1): 27-50, DOI 10.1016/S0375-6505(99)00049-8.

Yund RA, Blanpied ML, Tullis TE and Week JD, 1990. Amorphous material in high strain experimental fault gouges. Journal of Geophysical Research 95(B10): 15589-15602, DOI 10.1029/JB095iB10p15589. 